\title{
1 Aromaticity and degree of aromatic condensation of char
}

3 Daniel B. Wiedemeiera*, Samuel Abiven ${ }^{a}$, William C. Hockaday ${ }^{\text {, }}$, Marco

4 Keiluweitc $^{\mathrm{c}}$, Markus Kleberc, Caroline A. Masiello ${ }^{\mathrm{d}}$, Anna V. McBeathe, Peter S.

5 Nicof, Lacey A. Pyled, Maximilian P. W. Schneidera, Ronald J. Smernike, Guido

6 L. B. Wiesenberga, Michael W. I. Schmidta

7 a Department of Geography, University of Zurich, 8057 Zurich, Switzerland

8 b Department of Geology, Baylor University, Waco, TX 76798, USA

9 c Department of Crop and Soil Science, Oregon State University, Corvallis, OR 10 97331, USA

11 d Department of Earth Science, Rice University, Houston, TX 77005, USA

12 e School of Agriculture, Food and Wine, University of Adelaide, Adelaide, SA

13 5064, Australia

14 f Earth Sciences Division, Lawrence Berkeley National Laboratory, Berkeley, 15 CA 94720, USA

16

17 * Corresponding author. Tel.: (+41) 446355228.

$18 \quad E$ mail address: daniel.wiedemeier@geo.uzh.ch (D. Wiedemeier). 
ABSTRACT

20 The aromatic carbon structure is a defining property of chars and is often

21 expressed with the help of two concepts: (i) aromaticity and (ii) degree of

22 aromatic condensation. The varying extent of these two features is assumed to

23 largely determine the relatively high persistence of charred material in the

24 environment and is thus of interest for e.g. biochar characterization or carbon

25 cycle studies. Consequently, a variety of methods has been used to assess the

26 aromatic structure of chars, which has led to interesting insights but has

27 complicated the comparison of data acquired with different methods. We

28 therefore used a suite of seven methods (elemental analysis, MIR spectroscopy,

29 NEXAFS spectroscopy, ${ }^{13} \mathrm{C}$ NMR spectroscopy, BPCA analysis, lipid analysis

30 and helium pycnometry) and compared 13 measurements from them using a

31 diverse sample set of 38 laboratory chars. Our results demonstrate that most of

32 the measurements could be categorized either into those which assess

33 aromaticity or those which assess the degree of aromatic condensation. A

34 variety of measurements, including relatively inexpensive and simple ones,

35 reproducibly captured the two aromatic features in question, and data from

36 different methods could therefore be compared. Moreover, general patterns

37 between the two aromatic features and the pyrolysis conditions were revealed, 38 supporting reconstruction of the highest heat treatment temperature (HTT) of 39 char. 


\section{KEYWORDS}

43 Pyrogenic organic matter, char, aromaticity, aromatic condensation, pyrolysis,

44 stability, heat treatment temperature, biochar

45

46

47 


\section{Introduction}

49 Natural and anthropogenic chars have recently received much attention

50 (Knicker, 2011; Glaser and Birk, 2012; Manyà, 2012). Their role as important

51 environmental constituents is increasingly being recognized; chars persist in

52 soils and sediments, which has important implications for the global $\mathrm{C}$ budget

53 (Schmidt and Noack, 2000) and they can exert beneficial properties on soils,

54 improving fertility (Biederman and Harpole, 2013) and immobilizing hazardous

55 compounds (Beesley et al., 2011). Moreover, anthropogenic chars (biochars)

56 involve additional economic advantages; prudent biochar production can

57 provide green energy, providing an interesting alternative to management of

58 organic wastes (Meyer et al., 2011).

59 With increasing interest in the use of charred material, there is a growing

60 need to characterize and classify the material accurately in order to improve

61 understanding of its properties and behavior in the environment. A defining

62 property of chars and of pyrogenic organic matter in general (Preston and

63 Schmidt, 2006) is their aromatic C structure (Lehmann and Joseph, 2009),

64 which is believed to consist of at least two different aromatic C phases: (i) an

65 amorphous phase comprising randomly organized aromatic rings and (ii) a

66 crystalline phase, comprising condensed polyaromatic sheets that are

67 turbostratically aligned (Franklin, 1951; Cohen-Ofri et al., 2006; Keiluweit et

68 al., 2010). The concepts of aromaticity (the total proportion of aromatic C

69 including both phases; McNaught and Wilkinson, 1997) and that of the degree 
70 of aromatic condensation (the proportion of the condensed aromatic $\mathrm{C}$ only;

71 McBeath et al., 2011) relate to this two phase model. The varying extent of the

72 two phases is believed to largely determine stability of the charred material

73 against degradation in the environment (Lehmann et al., 2009; Singh et al.,

74 2012). Consequently, aromaticity and the degree of aromatic condensation of a

75 char likely influence its sequestration potential as well as the duration during

76 which it can provide benefits to the soil (Nguyen et al., 2010).

77 The two features are themselves influenced by the feedstock, and the

78 pyrolysis conditions. The type of feedstock contributes to the aromaticity and

79 the degree of aromatic condensation by providing different chemical structures

80 as starting material. For example, a high amount of aromatic structures in a

81 feedstock (e.g. lignin in wood) can promote the resulting char aromaticity

82 (Antal and Grønli, 2003). Similarly, different precursor materials attain a high

83 degree of aromatic condensation at different temperatures (Setton et al., 2002).

84 The pyrolysis conditions, in particular the highest heat treatment temperature

85 (HTT), but also residence time, $\mathrm{O}_{2}$ availability and pressure influence the $\mathrm{C}$

86 properties of the resulting char (Shafizadeh, 1982; Lua et al., 2004).

87 Aromaticity has been reported to increase with HTT from $200{ }^{\circ} \mathrm{C}$ to ca. $500{ }^{\circ} \mathrm{C}$,

88 where maximum aromaticity values are reached. The degree of aromatic

89 condensation showed, on the other hand, a more gradual increase with HTT

90 from $400{ }^{\circ} \mathrm{C}$, reaching maximum values at $>1000{ }^{\circ} \mathrm{C}(\mathrm{McBeath}$ et al., 2011 ;

91 Schneider et al., 2011). 
92 Considering the importance of the aromatic $\mathrm{C}$ structure in char and its

93 dependency on many influencing factors, it is not surprising that various

94 attempts have been made to measure these archetypal properties of char. A

95 wide variety of chemical and physical methods has been used, including

96 elemental analysis, molecular markers, solid state ${ }^{13} \mathrm{C}$ nuclear magnetic

97 resonance (NMR) spectroscopy, infrared (IR) spectroscopy, Raman

98 spectroscopy, pyrolysis-gas chromatography-mass spectrometry (Py-GC-MS),

99 X-ray diffraction, near edge X-ray absorption fine-structure spectroscopy

100 (NEXAFS), X-ray photoelectron spectroscopy, measurements of surface area,

101 He based solid density, electrical resistivity or high resolution transmission

102 electron microscopy (HRTEM) (Derenne et al., 2005; McBeath et al., 2011;

103 Charon et al., 2014).

104 While the wealth of methods for aromatic structure characterization of char

105 is fascinating, with the methods continuing to grow in number and quality, it

106 has become increasingly difficult to compare data using different methods and

107 to relate the findings from them. Matters are complicated by the fact that

108 terms such as aromaticity can have multiple technique-specific meanings

109 (McBeath et al., 2011). Moreover, from a practical point of view, researchers

110 and practitioners may have limited resources and instrumentations and would

111 like to optimize both insightful data acquisition and reasonable analysis cost.

112 Efforts to compare different methods and their measurements and to put them

113 in a common framework are therefore required, thereby guiding the 
114 interpretation of differently acquired data and suggesting suitable methods for 115 specific analysis problems.

116 Here, we have used an extensive suite of 7 different methods that provided

11713 measurements (cf. Table 1) in a comparative study to evaluate their

118 assessment of the aromatic structure in charred materials. A large sample set, 119 consisting of 38 different laboratory char samples (cf. Table 2), was analyzed

120 using each method. The objective was to show and discuss how the 7 methods

121 and their measurements capture the aromatic structures in the largely

122 different chars and how they compare with each other. Moreover, we aimed to

123 reveal the influence of feedstock, HTT and other pyrolysis parameters on

124 aromaticity and degree of aromatic condensation, by statistically exploring the 125 rich dataset from this large scale comparative study. 


\section{Material and methods}

\subsection{Char thermosequences}

130 Four different feedstocks (chestnut wood, pine wood, fescue grass and rice

131 grass) and two different pyrolysis procedures (A, $5 \mathrm{~h}$ residence time at HTT 132 with continuous $\mathrm{N}_{2}$ flow; $\mathrm{B}, 1 \mathrm{~h}$ residence time at $\mathrm{HTT}$ in a closed chamber) 133 were used to create 38 laboratory char samples with HTT between 100 and $1341000{ }^{\circ} \mathrm{C}\left(\mathrm{A}, 200-1000{ }^{\circ} \mathrm{C} ; \mathrm{B}, 100-700{ }^{\circ} \mathrm{C}\right)$, as reported in detail in two 135 previous studies (Keiluweit et al., 2010; Schneider et al., 2011). The resulting

136 char thermosequences (Wood-A, Grass-A, Wood-B, Grass-B) are displayed in 137 Table 2.

2.2. Methods, measurements and derived indices

140 The char samples were measured using elemental analysis, mid-IR (MIR)

141 spectroscopy, NEXAFS spectroscopy, ${ }^{13} \mathrm{C}$ NMR spectroscopy, benzene

142 polycarboxylic acid (BPCA) analysis, lipid analysis and He pycnometry, as

143 described in detail in the Supplementary data. Some of the methods provided

144 more than one measurement (e.g. elemental analysis gives $\mathrm{H} / \mathrm{C}$ and $\mathrm{O} / \mathrm{C}$ ratios), 145 as summarized in Table 1 . Because the measurements are in widely different 146 units and sometimes inversely proportional to each other, indices were built for 147 comparison purposes that project the data on a common scale $(0-1)$ and in the 148 same direction (0, lowest aromaticity or lowest degree of aromatic 149 condensation; 1, highest aromaticity or highest degree of aromatic 
150 condensation). Thus, each value $x$ of a measurement $M$ was transformed

151 according to Eq. 1 to provide $M_{\text {index }[0-1]}$. In the case of inversely proportional

152 measurements, denoted [1 - 0], they were further transformed according to Eq.

1532 to yield $M_{\text {index }_{[0-1]}}$. From here on, the methods and measurements are

154 referred to by their indices $\left(M_{\text {index }}\right)$, as listed in Table 1.

155

$156 M_{\text {index }[0-1] \text { or }[1-0]}=\frac{x_{M}-\min _{M}}{\max _{M}-\min _{M}}$

$157 M_{\text {index }_{[0-1]}}=1-M_{\text {index }_{[1-0]}}$

\subsection{Data presentation and statistical analysis}

160 The large set of original data can be found in the Supplementary data, while

161 we focus here on the most important findings, showing only simplified data for

162 reasons of clarity and understanding. All data analysis was conducted using

163 the statistical software R (2011). The few missing values (ca. 5\%) were imputed

164 with the missForest algorithm (Stekhoven and Buehlmann, 2012) with an

165 estimated normalized root mean square error of only $0.2 \%$. Principal

166 component analysis (PCA; Mardia et al., 1979) including biplots (Gabriel, 1971)

167 was computed on the correlation matrix of the inputed dataset.

168

169 


\section{Results and discussion}

171 All the methods provide measurements of physical or chemical variables

172 linked either to aromaticity or degree of aromatic condensation, but the link

173 between the variables and the derived aromatic features varies greatly.

174 Measuring ring current with NMR (NMR-condindex $)$ is, for example, a more

175 direct approach for assessing the degree of aromatic condensation than

176 measuring skeletal density of char with He pycnometry (Pycnoindex). However,

177 the methods differ not only in how they provide assessment of aromatic

178 structures but also in cost, availability and necessary expertise. Moreover,

179 sample amount and composition can prevent the use of one method and/or

180 promote the application of another. For these reasons, the aim was not to

181 identify a reference method via inferential statistics or cost benefit analysis but

182 rather to show method performance and explore qualitatively method

183 similarities and differences within the two categories of aromaticity and

184 aromatic condensation. The standardized measurement results from each

185 method (indices) are shown in full in Figs. 1 and 2 and mathematically

186 summarized according to their resemblance in form of a PCA, in Fig. 3.

$188 \quad$ 3.1. Aromaticity

189 Aromaticity in char is generally easier to assess than the degree of aromatic

190 condensation (McBeath et al., 2011). Thus, more methods are available for

191 measuring aromaticity than for measuring the degree of aromatic 
192 condensation (Figs. 1 and 3). In particular, the determination of elemental

193 composition $\left(\mathrm{O}-\mathrm{C}_{\text {index }}, \mathrm{H}^{-} \mathrm{C}_{\text {index }}\right)$, the spectroscopic assessment of functional

194 groups $\left(\right.$ MIR $_{\text {index }}$, NEXAFS-aroma $\left.i n d e x, N M R-a r o m a a_{\text {index }}\right)$ and the measurement

195 of aromatic molecular markers $\left(\mathrm{BPCA}_{\text {index }}, \mathrm{PAH}_{\text {index }}\right)$ can yield insight into the

196 proportion of aromatic $\mathrm{C}$ in chars (Table 1). Non-aromatic molecular markers

197 (TLE $E_{\text {index }}, \mathrm{ACL}_{\text {index }}$ ) may also be related to the proportion of aromatic $\mathrm{C}$ in chars

198 as charring also affects the composition of these moieties.

199 The $\mathrm{O}-\mathrm{C}_{\text {index }}$ and the $\mathrm{H}-\mathrm{C}_{\text {index }}$ are routine measurements for chars (Baldock

200 and Smernik, 2002; Hammes et al., 2006) and are an indirect measurement of

201 aromaticity because the proportion of $\mathrm{C}$ in a sample increases with HTT, as

202 dehydration, depolymerization and volatilization take place, eventually leading

203 to the formation of $\mathrm{H}$ and $\mathrm{O}$ depleted aromatic $\mathrm{C}$ structures (Keiluweit et al.,

204 2010; Wang et al., 2013).

205 The $\mathrm{O}^{-} \mathrm{C}_{\text {index }}$ of fresh chars depicts a characteristic trend for aromaticity

206 measurements (Fig. 1), because it traces closely the median of all aromatic

207 measurements and thereby shows a typical pattern for aromaticity in the

208 samples: The proportion of aromatic rings in a sample is lowest for low

209 temperature chars, then increases sharply between 200 and $500{ }^{\circ} \mathrm{C}$ and

210 reaches a plateau $>600{ }^{\circ} \mathrm{C}$. The increasing $\mathrm{O}^{-} \mathrm{C}_{\text {index }}$ reflects the elimination of

$211 \mathrm{O}$, mostly early in the charring process. The $\mathrm{O}^{-} \mathrm{C}_{\text {index }}$ also differentiates between

212 wood and grass char in the low temperature range (e.g. Wood-B vs. Grass-B).

213 This can be attributed to the higher lignin content of the wood feedstock 
214 (Rutherford et al., 2012). At high temperatures, the wood char samples again

215 acquire higher $\mathrm{O}^{-} \mathrm{C}_{\text {index }}$ values than the grass char samples. This probably

216 reflects the higher ash content of the latter, which tends to retard

217 aromatization (Mukome et al., 2013). Despite the fact that O content was

218 assessed differently between the different thermosequences (actual measured

219 O content for the A thermosequences vs. calculated by difference for the B

220 thermosequences - cf. Supplementary data), similar results were obtained in

221 both cases, indicating that the less expensive option of calculating $\mathrm{O}$ content by

222 difference may be sufficient for assessing aromaticity in most freshly produced

223 chars. However, measuring $\mathrm{O}$ by difference could be problematic for

224 aromaticity assessment of chars with high ash contents.

225 The $\mathrm{H}^{-} \mathrm{C}_{\text {index }}$ showed the lowest values for aromaticity in the lowest HTT

226 range at $100-200{ }^{\circ} \mathrm{C}$, as expected (Wang et al., 2013). Like the $\mathrm{O}^{-} \mathrm{C}_{\text {index }}$, it also

227 yields higher aromaticity for the lignin-rich wood char samples (Wood-B) than

228 the lignin-poor grass char samples (Grass-B) at these low temperatures. A

229 steep increase in aromaticity then followed from $200-500{ }^{\circ} \mathrm{C}$ HTT. However,

230 highest values for $\mathrm{H}^{-} \mathrm{C}_{\text {index }}$ based aromaticity were only reached at the highest

$231 \mathrm{HTT}\left(1000{ }^{\circ} \mathrm{C}\right)$, indicating that the $\mathrm{H}-\mathrm{C}_{\text {index }}$ is not a pure measurement for

232 aromaticity. In fact, the $\mathrm{H}^{-} \mathrm{C}_{\text {index }}$ is positioned at the edge of the aromaticity

233 measurements in Fig. 3 (vector number 9), relatively adjacent to the aromatic

234 condensation measurements. This also makes sense from a theoretical point of

235 view, because $\mathrm{H}$ is also lost during condensation of aromatic structures at high 
236 charring temperature (Franklin, 1951). Thus, the $\mathrm{H}^{-} \mathrm{C}_{\text {index }}$ probably indicates

237 both an increasing amount of aromatic rings, up to ca. $500{ }^{\circ} \mathrm{C}$ HTT, and then

238 the increasingly condensed nature of the aromatic rings, that continues to

239 develop at higher charring temperature.

240 There was a slight lag in aromaticity of the Wood-B and Grass-B

241 thermosequences vs. the Wood-A and Grass-A thermosequences with respect to

242 HTT; the two thermosequences that were charred for $5 \mathrm{~h}$ and with a $\mathrm{N}_{2}$ flow

243 (A) attain higher values of aromaticity at slightly lower HTT than the two

244 thermosequences that were charred for only $1 \mathrm{~h}$ in closed chambers (B). This

245 pattern was observed for most of the aromaticity measurements $\left(\mathrm{cf} . \mathrm{H}-\mathrm{C}_{\text {index }}\right.$,

246 NMR-aromaindex, BPCA $_{\text {index }}$, TLE $_{\text {index }}$ ) and is independent of feedstock (grass vs.

247 wood). Thus, it appears to be related to the pyrolysis method, indicating that

248 the longer residence times of pyrolysis procedure A charred the samples more

249 completely at the same HTT than the shorter residence times in procedure B.

250 The slight difference in pyrolysis procedures proved useful in this study

251 because it allowed us to check if the various methods detect this feature.

252 The MIR $_{\text {index }}$ distinguished low temperature chars from high temperature

253 chars, with an increase in aromaticity between 300 and $500{ }^{\circ} \mathrm{C}$, as similarly

254 observed by Harvey et al. (2012a). It can thus serve as a quick and relatively

255 inexpensive screening method for categorizing unknown char samples roughly

256 according to their aromaticity and HTT. However, the MIR index $_{\text {used here only }}$

257 qualifies as a rough estimate for aromaticity, given its large variability for 
258 chars $>300^{\circ} \mathrm{C}$, which can also be seen from the shorter length of vector 5 in

259 Fig. 3. Moreover, the $\mathrm{MIR}_{\text {index }}$ seems to depend on the pyrolysis procedure in

260 this mid- and high-temperature range, which was not reproduced by any of the

261 other methods. The data show that MIR has the potential to measure

262 aromaticity and possibly other HTT dependent variables, but clearly requires

263 more research and fine tuning with respect to IR band selection and spectral

264 data analysis.

265 The NEXAFS-aromaindex has been similarly used to describe the B

266 thermosequence chars elsewhere (Keiluweit et al., 2010) and was in the frame

267 of the comparative study now also applied to part of the A thermosequence

268 chars. In the case of the A thermosequence, the NEXAFS-aromaindex increased

269 between 600 and $1000{ }^{\circ} \mathrm{C}$. This is unlike most other aromaticity measurements

270 that show a pronounced increase in aromaticity at lower HTT. The NEXAFS-

271 aroma $a_{\text {index }}$ also gave higher aromaticity values for the Grass-A chars than the

272 Wood-A chars; this is in contrast to most other observations but in line with

273 previous results from NEXAFS applications (Keiluweit et al., 2010). In the case

274 of the B thermosequence, the NEXAFS-aromaindex behaved unexpectedly in the

275 low temperature range, indicating high aromaticity values for almost unaltered

276 feedstock and showing decreasing aromaticity with increasing HTT. The reason

277 for the unexpected behavior of the NEXAFS indices is discussed below in

278 Section 3.2. 
279 Using NMR is a recently established means for assessing aromaticity of 280 charred samples (McBeath et al., 2011). The NMR-aromaindex determined the 281 wood char samples in the low-temperature range $\left(100-200{ }^{\circ} \mathrm{C}\right)$ as being more 282 aromatic than the grass char samples, like the $\mathrm{H}^{-} \mathrm{C}_{\text {index }}$ and $\mathrm{O}^{-} \mathrm{C}_{\text {index }}$, and then 283 also showed the typical increase in aromaticity between 200 and $500{ }^{\circ} \mathrm{C}$, 284 reaching a plateau from $600{ }^{\circ} \mathrm{C}$ for all feedstocks and pyrolysis methods, with 285 little variability. Since NMR measures directly the organic C bonds, it is not 286 sensitive to ash content, yielding equally high values for high temperature 287 wood and grass chars. A small shift between the differently pyrolysed 288 thermosequences (A vs. B) could also be observed where aromaticity increased, 289 further, corroborating the idea that the two pyrolysis procedures produced 290 slightly different chars in the mid-temperature range.

291 The BPCA method separates and quantifies aromatic moieties that originate 292 from condensed aromatic structures, which is why it is insensitive to lignin. 293 Thus, the BPCA-aromaindex scored very low for both wood and grass chars in 294 the range up to $200^{\circ} \mathrm{C}$. It then increased steadily with $\mathrm{HTT}$ up to $500{ }^{\circ} \mathrm{C}$, 295 where maximum values were reached, and decreased slightly from $700{ }^{\circ} \mathrm{C}$ 296 onwards. The trend at low and mid-temperatures was consistent with the other 297 aromaticity measurements, while the slight decrease at high temperature was 298 inconsistent with the expected high aromaticity at high HTT. This can be 299 attributed to a method artifact from which BPCA-aromaindex suffers: highly 300 condensed aromatic structures are not completely converted to quantifiable 
301 BPCAs and thus, as condensation increases above $600{ }^{\circ} \mathrm{C}$, the BPCA-aromaindex

302 declines slightly (Schneider et al., 2010). Still, it is able to distinguish the high

303 temperature chars (grass vs. wood) and also the effect of the two different

304 pyrolysis procedures $\mathrm{A}$ and $\mathrm{B}$, which is why the BPCA-aromaindex plots well

305 within the aromaticity vector in Fig. 3.

306 The lipid indices $\left(\mathrm{TLE}_{\text {index }}, \mathrm{ACL}_{\text {index }}, \mathrm{PAH}_{\text {index }}\right)$ are indirectly linked to

307 changes in aromaticity because the lipid proportion (e.g. $\operatorname{TLE}_{\text {index }}$ ) and quality

308 (e.g. $\mathrm{ACL}_{\text {index }}, \mathrm{PAH}_{\text {index }}$ ) vary with $\mathrm{HTT}$ and the associated changes in

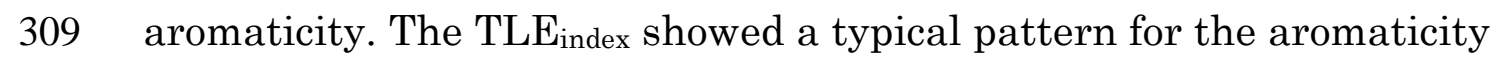

310 measurements, with low values (high extractability) at low temperatures and

311 high values (low extractability) $>600{ }^{\circ} \mathrm{C}$. Simple lipid extraction thus seemed

312 to be a good proxy for aromaticity. It was able to differentiate between the two

313 pyrolysis methods, showing the delayed increase in aromaticity of the B

314 thermosequences, and remained at a constant maximum $>600{ }^{\circ} \mathrm{C}$. However, it

315 suffered from too high index values at low HTT for all thermosequences except

316 the Grass-A thermosequence. This is probably due to the generally low content

317 of extractable lipids in woody tissue (Gocke et al., 2013).

318 The ACL of alkanes decreased with increasing HTT due to cracking of carbon

319 bonds (Simoneit and Elias, 2000; Wiesenberg et al., 2009), which translates

320 into an increasing trend in the reciprocal $\mathrm{ACL}_{\text {index }}$ with increasing temperature.

321 The ACL $\mathrm{L}_{\text {index }}$ showed the general pattern of the other aromaticity

322 measurements, e.g. pronounced increase in the index between 200 and $600{ }^{\circ} \mathrm{C}$, 
323 a higher lignin-derived aromaticity for woody low temperature chars than

324 grassy chars and the characteristic difference between the two pyrolysis

325 procedures between 200 and $600{ }^{\circ} \mathrm{C}$. However, while the $\mathrm{ACL}_{\text {index }}$ was similar

326 to other aromaticity measurements for the Grass-A thermosequence, it showed

327 a high variability between the different thermosequences and sometimes no

328 characteristic trend was observable at all (e.g. for the Wood-A

329 thermosequence). These important drawbacks do not seem to depend on

330 pyrolysis method or two types of starting material (wood vs. grass) but rather

331 seem dependent on each of the four individual feedstocks. Thus, using ACLindex

332 as an aromaticity measurement requires a careful calibration according to

333 feedstock before conclusions can be drawn from it.

334 The $\mathrm{PAH}_{\text {index }}$ is another measurement theoretically linked to aromaticity in 335 chars and which can be retrieved after lipid extraction (Simoneit, 2002; Yunker

336 et al., 2002). Despite its rather straightforward concept of comparing larger

337 with smaller PAH structures, no monotonic trend with HTT was observed.

338 Instead, a maximum of the $\mathrm{PAH}_{\text {index }}$ was found at $400-500{ }^{\circ} \mathrm{C}$, which

339 interestingly correlates with total solvent-extractable PAH yield, as found in a

340 more detailed study by Keiluweit et al. (2012). These results indicate that the

341 relationship between PAH composition and HTT of chars is rather complex

342 (Wiedemeier et al., 2014) and requires more research. 


\subsection{Degree of aromatic condensation}

345 We assessed the degree of aromatic condensation by investigating functional

346 groups and atomic bonds (NMR-cond $d_{\text {index }}$, NEXAFS-cond $d_{\text {index }}$ ), quantifying

347 molecular markers $\left(\mathrm{BPCA}^{-}\right.$-cond $\left._{\text {index }}\right)$ and measuring the structural density

348 (Pycnoindex) of the chars (Table 1).

349 The NMR method is the most recent development in the field and had

350 already afforded plausible results on one set of the chars (Wood-A

351 thermosequence; McBeath et al., 2011). In the same study, it was shown that

352 the degree of aromatic condensation increases more gradually with increasing

353 HTT than aromaticity and that a high degree of condensation only occurs at

354 high HTT. Here, the inclusion of the Grass-A, Wood-B and Grass-B

355 thermosequences again showed a similar pattern: the degree of aromatic

356 condensation was minimal up to $250{ }^{\circ} \mathrm{C}$ and then constantly and monotonically

357 increased up to the highest HTT. Interestingly, the chars from the B pyrolysis

358 procedure again lagged behind those from the A pyrolysis procedure, indicating

359 that the shorter pyrolysis time not only reduced the aromaticity but also the

360 degree of aromatic condensation.

361 The BPCA method reproduced the NMR-condindex general pattern

362 consistently, despite the large difference in methodology. The relationship

363 between the degree of aromatic condensation and HTT was more curved than

364 that for NMR, pointing to a slightly non-linear behavior of the BPCA-condindex.

365 This minor deviation is probably method inherent because it occurred 
366

367

368

369

370

371

372

373 He pycnometry represents a third, completely independent approach for

374 assessing the degree of aromatic condensation. He can penetrate the smallest

375 of pores and can thus be used to assess the skeletal density (Brewer et al.,

376 2014), which increases with increasing molecular condensation. Despite its

377 lower cost and shorter analysis time, this indirect measurement appeared to

378 reproduce quite well the main trend from the above, more complex and

379 expensive aromatic condensation measurements. It depicted a rather linear

380 increase in aromatic condensation from $300^{\circ} \mathrm{C}$ up to the highest measured

381 HTT. He pycnometry measurements in the low temperature range $\left(<300^{\circ} \mathrm{C}\right)$

382 seem, however, to be less promising because the Pycnoindex overestimated

383 aromatic condensation for such mild heat treatment. Besides, the Wood-B

384 thermosequence showed unusual behavior, whereby only the highest HTT (700

$385{ }^{\circ} \mathrm{C}$ ) would be assigned as giving a condensed aromatic carbon structure.

386 The NEXAFS-cond $d_{\text {index }}$ indicated a pronounced increase in the degree of

387 aromatic condensation of the chars between 200 and $500{ }^{\circ} \mathrm{C}$ and a decrease 
388 above $600{ }^{\circ} \mathrm{C}$, which is not consistent with the other aromatic condensation 389 measurements (Fig. 3, vector 2). Both NEXAFS indices used here (NEXAFS-

390 aromaindex and NEXAFS-condindex ${ }$ ) showed different behavior compared with

391 other metrics of aromaticity and aromatic condensation. The use of simple

392 indices derived from NEXAFS spectra is most likely limited by the fact that

393 resonances in NEXAFS are not derived exclusively from specific functional

394 groups but rather are a result of the entire electronic structure of the char

395 material.

396

\subsection{General patterns of aromatic features and implications}

398 Applying a large suite of 7 methods with 13 measurements to a diverse char

399 sample set of four thermosequences enabled us to identify general patterns

400 between analytical methods and char C properties.

401 One observable pattern was the distinction between measurements that

402 assess aromaticity and those that assess the degree of aromatic condensation,

403 as discussed above and shown in Fig. 3. The differentiation was sharp and

404 resulted in two distinct trends with HTT as depicted in Fig. 1 and Fig. 2. The

405 two general trends across methods is best represented by the median of all

406 measurements for each category: aromaticity increased sharply from $200{ }^{\circ} \mathrm{C}$ on,

407 reaching maximum values at $500-600^{\circ} \mathrm{C}$, and stayed constant at the

408 maximum with higher HTT (Fig. 1, bottom right). The median of all aromatic

409 condensation measurements, on the other hand, increased smoothly from 300 
${ }^{\circ} \mathrm{C}$ on, reaching highest values at $1000{ }^{\circ} \mathrm{C}$ (Fig. 2, bottom left). While this

411 difference between the two categories of aromatic measures has been reported

412 elsewhere (McBeath et al., 2011), it was somewhat surprising how congruently

413 the methods behaved within each category, despite the fact that they are based

414 on fundamentally different approaches. The $\mathrm{O}-\mathrm{C}_{\text {index }}$, for example, followed the

415 NMR-aromaindex, with only very minor differences for all thermosequences, and

416 the $\mathrm{H}^{-} \mathrm{C}_{\text {index }}$, as well as the BPCA-aromaindex, gave very similar results.

417 Likewise, NMR-cond ${ }_{\text {index }}, \mathrm{BPCA}^{-}$-cond $_{\text {index }}$ and Pycno index $_{\text {were }}$ very similar for

418 the degree of aromatic condensation for all feedstocks and pyrolysis procedures.

419 Even the slight shift between pyrolysis procedure A and B with respect to HTT

420 was readily detected with most of the methods $\left(\mathrm{O}^{-} \mathrm{C}_{\text {index }}, \mathrm{H}^{-} \mathrm{C}_{\text {index }}, \mathrm{NMR}^{-}\right.$

421 aromaindex BPCA-aromaindex, TLE $_{\text {index }}, \mathrm{NMR}^{-}$cond $_{\text {index }}, \mathrm{BPCA}^{-}$-cond $_{\text {index }}$,

422 Pycnoindex ) reflecting both the importance of the pyrolysis conditions on the

423 char $\mathrm{C}$ properties and the high sensitivity of each measurement for differences

424 in char aromatic structure. Our observations imply that a variety of

425 measurements are suitable for assessing the aromatic $\mathrm{C}$ structure of chars and

426 that differently acquired data, e.g. from different research groups and

427 laboratories, can be compared if the data are reasonably standardized and

428 calibrated. More comparable data interpretations of diverse published and

429 future studies alike can lead to a more consistent and better understanding of

430 the $\mathrm{C}$ structure in different chars, which, in turn, promises to illuminate the $\mathrm{C}$ 
431 sequestration potential of diverse chars (Wang et al. 2013; Keiluweit et al.,

432 2010; Harvey et al., 2012b; Singh et al., 2012).

433 The distinctive and reproducibly measurable trends in aromaticity and

434 aromatic condensation as a function of HTT also allow the inverse examination

435 of chars: if the aim is to determine the unknown HTT of a certain char, it can

436 be estimated by measuring its aromatic $\mathrm{C}$ structure. A quick multiple linear

437 regression analysis of our dataset (data not shown) indicated that it is best to

438 combine a measurement of aromaticity with one of aromatic condensation to

439 obtain precise HTT reconstruction estimates. Aromaticity and aromatic

440 condensation increase over different ranges of temperature and thus yield

441 complementary information about the char HTT. Methods that provide both

442 aromatic measurements at the same time (e.g. NMR-aromaindex and NMR-

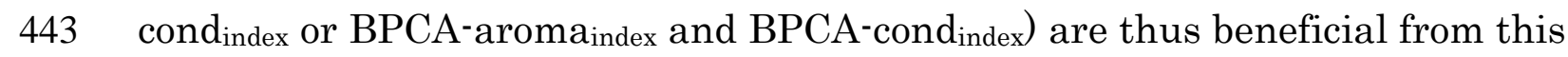

444 point of view. However, similarly good results for HTT reconstruction were

445 achieved by combining different methods, e.g. the $\mathrm{O}-\mathrm{C}_{\text {index }}$, which captures

446 aromaticity, with the Pycnoindex, which measures the degree of aromatic

447 condensation. HTT reconstruction of chars may be an important application of

448 the above methods in archeological studies (Conedera et al., 2009; Wolf et al.,

$4492013)$ in addition to the more established focus on char stability in an

450 environmental context (Nguyen et al., 2010; Al-Wabel et al., 2013).

451 We conclude that some indirect, relatively inexpensive and simple methods

452 (e.g. elemental analysis or He pycnometry) captured the aromatic structures in 
453 fresh chars similarly as well as more costly and time-consuming techniques.

454 This holds promise, whereby aromaticity and the degree of aromatic

455 condensation can be readily assessed in all kinds of char studies and with a

456 variety of new and established methods. Thus, characterization and

457 classification of charred materials should explicitly take these two C aromatic

458 features into account because they are likely key to their stability against

459 degradation in the environment as well as being .informative about production

460 temperature.

461

462

463

464

465 


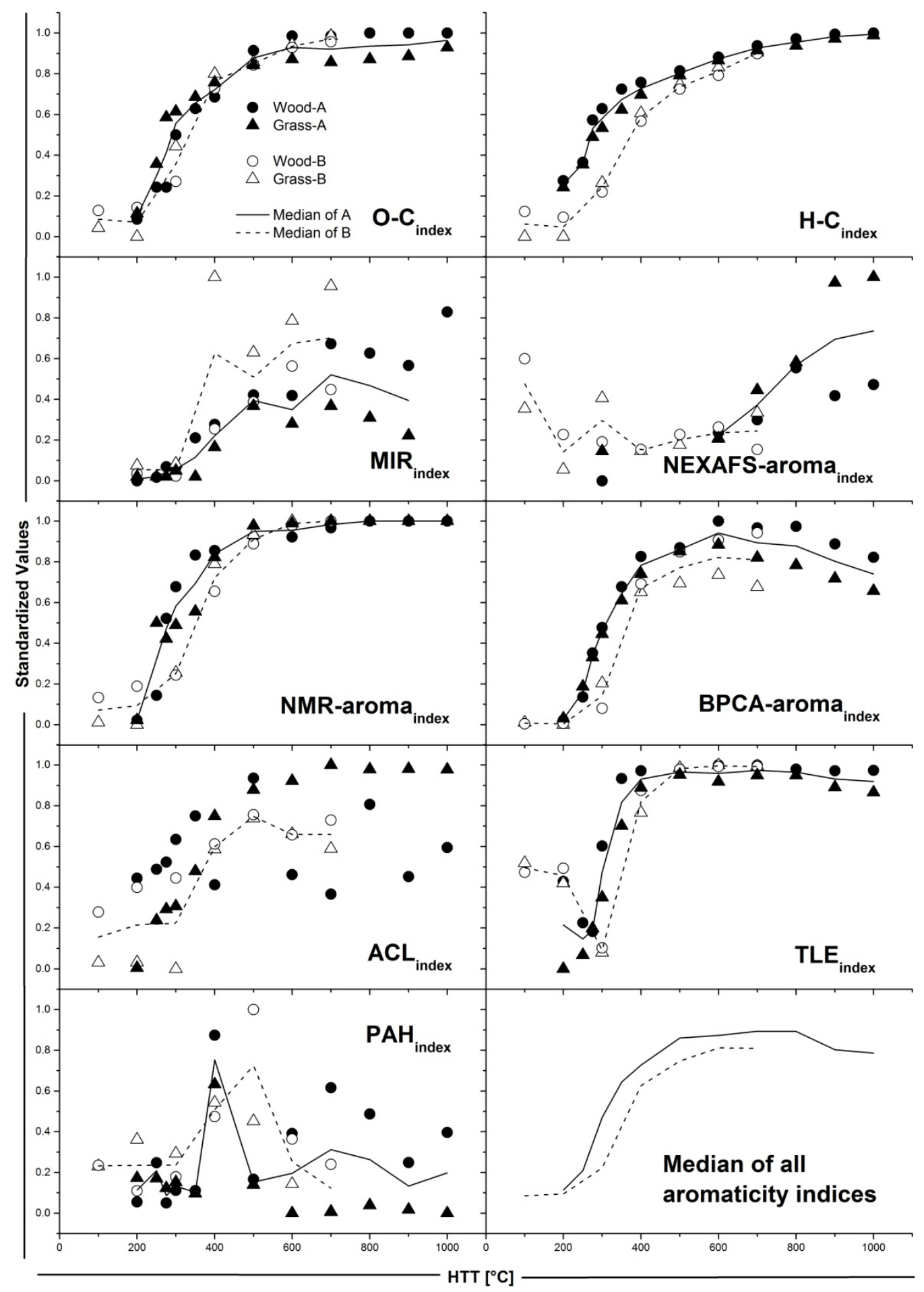

Figure 1. 


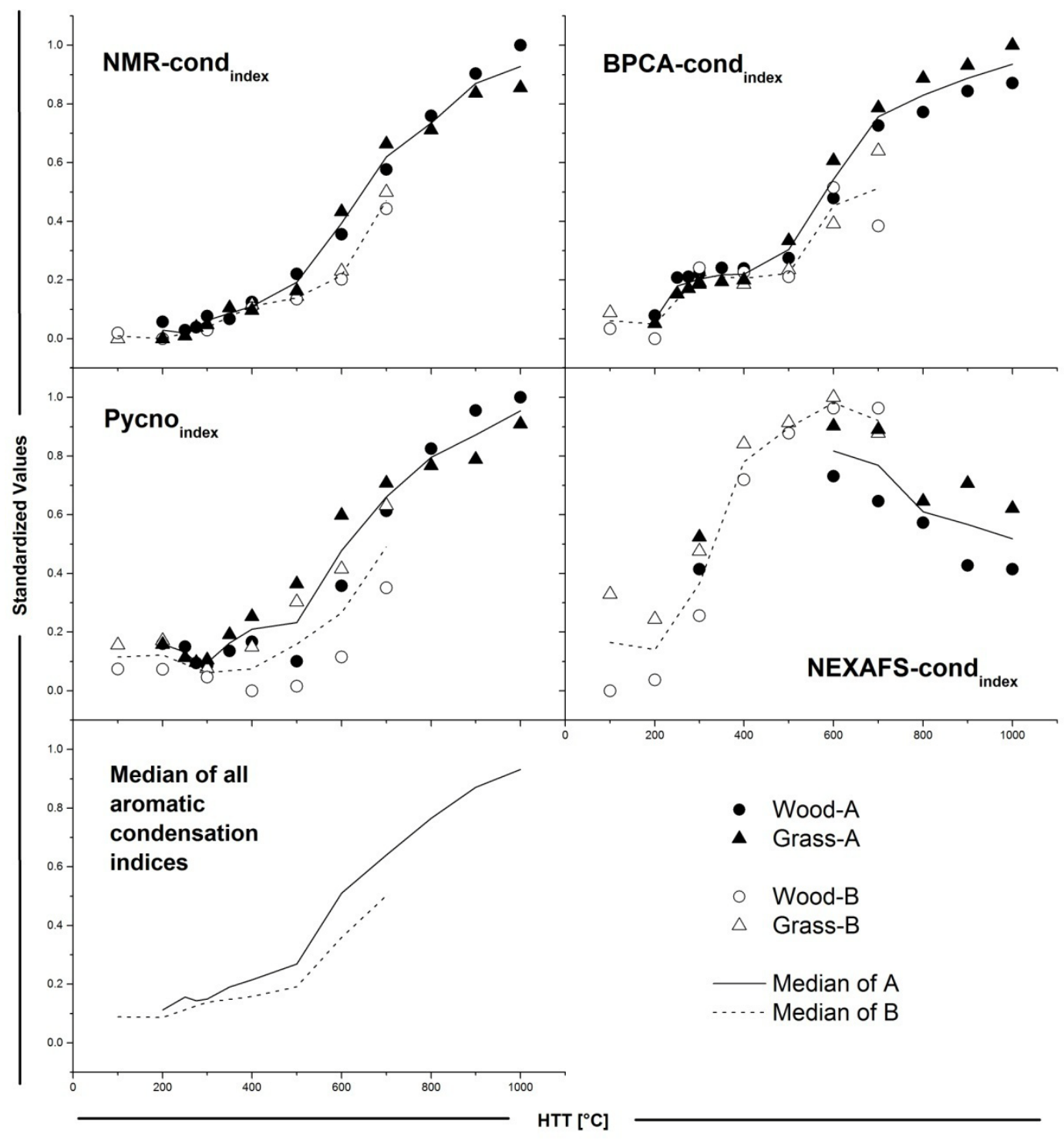

469

Figure 2. 


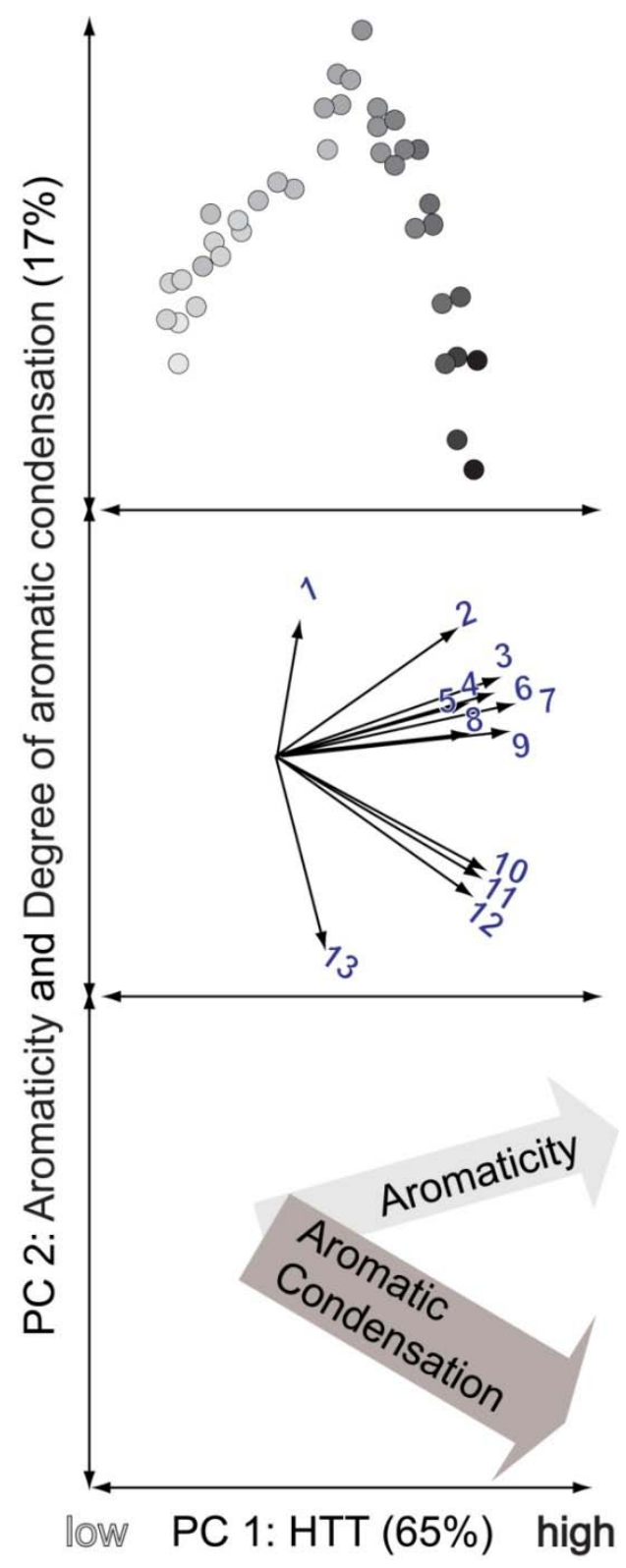

471

$472 \quad$ Figure 3.

473

474 
476 Fig. 1. Char aromaticity as measured via nine different indices. The median of

477 all the indices is shown at the lower right corner and thus describes the typical 478 trend in aromaticity with HTT.

480 Fig. 2. Degree of aromatic condensation as measured via four different indices.

481 The median of all the aromatic condensation indices is depicted in the lower 482 left and thus shows a typical increase in degree of aromatic condensation with 483 HTT.

485 Fig. 3. PCA of the large dataset generated. The first PC is projected along the 486 HTT axis and thus differentiates the chars according to heating temperature. 487 The darker the circle symbol for a sample, the higher its HTT (top). The second 488 PC spreads between aromaticity and the degree of aromatic condensation, 489 showing that the char samples first become more aromatic with increasing 490 HTT and then increase in aromatic condensation in the higher temperatures 491 range (top). Likewise, the PCA differentiates between the different 492 measurements (center and bottom) and groups them into typical aromaticity 493 indices $(3-9)$ and typical indices for assessing the degree of aromatic 494 condensation $(10-12)$. The numbers indicate: $1, \mathrm{PAH}_{\text {index }} ; 2$, NEXAFS- 
495 cond $_{\text {index }} ; 3, \mathrm{BPCA}-$ aroma $_{\text {index }} ; 4, \mathrm{TLE}_{\text {index }} ; 5, \mathrm{MIR}_{\text {index }} ; 6, \mathrm{O}^{-\mathrm{C}_{\text {index }}} ; 7, \mathrm{NMR}-$

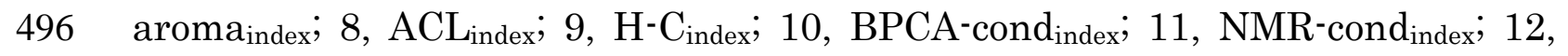
$497 \quad$ Pycno $_{\text {index }} ; 13$, NEXAFS-aroma $a_{\text {index. }}$ 


\section{TABLES}

\section{Table 1}

501 Methods considered comparatively for assessing aromaticity and/or degree of aromatic condensation of chars 502 (names of derived indices in bold).

\begin{tabular}{|c|c|c|c|c|}
\hline Measurement principle & Method & Index $\left(M_{\text {index }}\right)$ & Measurement & Reference \\
\hline Elemental composition & Elemental analysis & $\begin{array}{l}\text { O- } \mathrm{C}_{\text {index }} \\
\mathrm{H}-\mathrm{C}_{\text {index }}\end{array}$ & $\mathrm{C}, \mathrm{H}$ and $\mathrm{O}$ content $(\%): \mathrm{H} / \mathrm{C}, \mathrm{O} / \mathrm{C}$ & $\begin{array}{l}\text { Baldock and Smernik (2002); } \\
\text { Hammes et al. (2006) }\end{array}$ \\
\hline \multirow[t]{4}{*}{ Functional groups } & Mid-infrared spectroscopy (MIR) & $\mathrm{MIR}_{\text {index }}$ & Aromaticity ratio $(\%):(1420+821) /(1510+1320) \mathrm{cm}^{-1}$ & $\begin{array}{l}\text { Wood (1988); Guo and Bustin (1998); } \\
\text { Moore and Owen (2001) }\end{array}$ \\
\hline & $\begin{array}{l}\text { Near-edge X-ray absorption fine } \\
\text { structure spectroscopy (NEXAFS) }\end{array}$ & $\begin{array}{l}\text { NEXAFS-aroma } \\
\text { NEXAFS-cond } \\
\text { NEAdex }\end{array}$ & $\begin{array}{l}\text { Aromaticity ratio (\%): } 285 \mathrm{eV} / 286-288 \mathrm{eV} \\
\text { Degree of condensation ratio (\%): } 284 \mathrm{eV} / 285 \mathrm{eV}\end{array}$ & $\begin{array}{l}\text { Francis and Hitchcock (1992); Agren et al. (1995); } \\
\text { Kuznetsova et al. (2001); Brandes et al. (2008); } \\
\text { Keiluweit et al. (2010) }\end{array}$ \\
\hline & $\begin{array}{l}{ }^{13} \mathrm{C} \text { Nuclear magnetic resonance } \\
\text { spectroscopy (NMR) }\end{array}$ & NMR-aroma index $_{1}$ & Deconvolution on fitted spectrum with assigned aromatic peaks & $\begin{array}{l}\text { McBeath and Smernik (2009); } \\
\text { McBeath et al. (2011) }\end{array}$ \\
\hline & - with sorbed ${ }^{13} \mathrm{C}$ label & NMR-cond index $_{\text {}}$ & $-\Delta \delta(\mathrm{ppm}):$ Shift of sorbed ${ }^{13} \mathrm{C}$ labelled benzene - shift of benzene & \\
\hline \multirow[t]{4}{*}{ Molecular markers } & $\begin{array}{l}\text { Benzene polycarboxylic acid } \\
\text { (BPCA) analysis }\end{array}$ & $\begin{array}{l}\text { BPCA-aroma } \\
\text { BPCA-x } \\
\text { BPCAnd }_{\text {index }}\end{array}$ & $\begin{array}{l}\text { Total BPCA amount per organic carbon }\left(\mathrm{g} \mathrm{kg}^{-1}\right) \text { : BPCA/C } \\
\text { Ratio of B6CA per total BPCA amount (\%): B6CA/BPCA }\end{array}$ & $\begin{array}{l}\text { Schneider et al. (2011); } \\
\text { Wiedemeier et al. (2013) }\end{array}$ \\
\hline & Lipid analysis & TLE $_{\text {index }}$ & Total lipid extract yield (g): TLE & $\begin{array}{l}\text { Wiesenberg et al. (2009); Wiesenberg et al. (2010); } \\
\text { Wiedemeier et al. (2014) }\end{array}$ \\
\hline & - $n$-alkanes & $A C L_{\text {index }}$ & Average chain length: $A C L$ & \\
\hline & - polycyclic aromatic hydrocarbons & $\mathrm{PAH}_{\text {index }}$ & Ratio of 4-6 ring to 2-3 ring polycyclic aromatic hydrocarbons (\%) & \\
\hline Density & He pycnometry & Pycno $_{\text {index }}$ & Skeletal density $\left(\mathrm{g} \mathrm{cm}^{-3}\right)$ & $\begin{array}{l}\text { Brown et al. (2006); Brewer et al. (2009); } \\
\text { Brewer et al. (2014) }\end{array}$ \\
\hline
\end{tabular}


$504 \quad$ Table 2

505 Thermosequences measured with each method.

506

\begin{tabular}{|c|c|c|c|c|}
\hline Feedstock & Pyrolysis Procedure & HTT & $\mathrm{n}$ & Thermosequence \\
\hline $\begin{array}{l}\text { Chestnut (Wood) } \\
\text { (Castanea sativa) }\end{array}$ & & $200-1000{ }^{\circ} \mathrm{C}$ & 12 & Wood-A \\
\hline $\begin{array}{l}\text { Rice (Grass) } \\
\text { (Oryza sativa) }\end{array}$ & 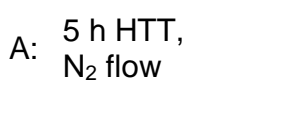 & $200-1000^{\circ} \mathrm{C}$ & 12 & Grass-A \\
\hline $\begin{array}{l}\text { Pine (Wood) } \\
\text { (Pinus ponderosa) }\end{array}$ & & $100-700{ }^{\circ} \mathrm{C}$ & 7 & Wood-B \\
\hline $\begin{array}{l}\text { Fescue (Grass) } \\
\text { (Festuca arundinacea) }\end{array}$ & $\begin{array}{l}1 \mathrm{~h} \text { HTT, } \\
\text { B: Closed Chamber }\end{array}$ & $100-700^{\circ} \mathrm{C}$ & 7 & Grass-B \\
\hline
\end{tabular}

507

508

509

510 


\section{Author Contributions}

513 D.B.W. compiled and analyzed the data, and wrote the paper. M.W.I.S.

514 conceived and coordinated the comparative study. Samples were provided by

515 M.P.W.S., M.Ke and M.Kl. Analysis was performed by S.A. (MIR), A.V.M., R.J.S.

516 and W.C.H (NMR), M.Ke and P.S.N. (NEXAFS), L.A.P. and C.A.M.

517 (pycnometry), M.P.W.S. and A.V.M. (BPCA), G.L.B.W. (lipid analysis). All

518 authors provided input into the drafting and the final version of the

519 manuscript.

520

521 Acknowledgments

522 Support for M.W.I.S. was also provided by the US Department of Energy

523 (contract no. DE-AC02-05CH11231). B. H. Meier (Laboratory of Physical

524 Chemistry ETH) made available NMR instruments. C.A.M acknowledges

525 support from NSF EAR-0911685. We thank S. Derenne an anonymous

526 reviewer for providing constructive comments that improved the manuscript.

527 Associate Editor - S. Derenne 


\section{References}

529 Agren, H., Vahtras, O., Carravetta, V., 1995. Near-edge core photoabsorption in 530 polyacenes - model molecules for graphite. Chemical Physics 196, 47-58.

531 Al-Wabel, M.I., Al-Omran, A., El-Naggar, A.H., Nadeem, M., Usman, A.R.A., 532 2013. Pyrolysis temperature induced changes in characteristics and chemical 533 composition of biochar produced from conocarpus wastes. Bioresource 534 Technology 131, 374-379.

535 Antal, M.J., Grønli, M., 2003. The art, science, and technology of charcoal 536 production. Industrial \& Engineering Chemistry Research 42, 1619-1640.

537 Baldock, J., Smernik, R., 2002. Chemical composition and bioavailability of 538 thermally altered Pinus resinosa (Red pine) wood. Organic Geochemistry 33, 539 1093-1109.

540 Beesley, L., Moreno-Jiménez, E., Gomez-Eyles, J.L., Harris, E., Robinson, B., 541 Sizmur, T., 2011. A review of biochars' potential role in the remediation, 542 revegetation and restoration of contaminated soils. Environmental Pollution 543 159, 3269-3282.

544 Biederman, L.A., Harpole, W.S., 2013. Biochar and its effects on plant 545 productivity and nutrient cycling: a meta-analysis. GCB Bioenergy 5, 202-214.

546 Brandes, J., Cody, G., Rumble, D., Haberstroh, P., Wirick, S., Gelinas, Y., 2008.

547 Carbon K-edge XANES spectromicroscopy of natural graphite. Carbon 46, $548 \quad 1424-1434$.

549 Brewer, C.E., Chuang, V.J., Masiello, C.A., Gonnermann, H., Gao, X., Dugan, 550 B., Driver, L.E., Panzacchi, P., Zygourakis, K., Davies, C.A., 2014. New 
551 approaches to measuring biochar density and porosity. Biomass and Bioenergy $55266,176-185$.

553 Brewer, C., Schmidt Rohr, K., Satrio, J., Brown, R., 2009. Characterization of 554 biochar from fast pyrolysis and gasification systems. Environmental Progress 555 \& Sustainable Energy 28, 386-396.

556 Brown, R.A., Kercher, A.K., Nguyen, T.H., Nagle, D.C., Ball, W.P., 2006.

557 Production and characterization of synthetic wood chars for use as surrogates

558 for natural sorbents. Organic Geochemistry 37, 321-333.

559 Charon, E., Rouzaud, J.N., Aléon, J., 2014. Graphitization at low temperatures

560 (600-1200 C) in the presence of iron implications in planetology. Carbon 66, $561 \quad 178-190$.

562 Cohen-Ofri, I., Weiner, L., Boaretto, E., Mintz, G., Weiner, S., 2006. Modern 563 and fossil charcoal: aspects of structure and diagenesis. Journal of 564 Archaeological Science 33, 428-439.

565 Conedera, M., Tinner, W., Neff, C., Meurer, M., Dickens, A.F., Krebs, P., 2009. 566 Reconstructing past fire regimes: methods, applications, and relevance to fire 567 management and conservation. Quaternary Science Reviews 28, 555-576.

568 Derenne, S., Rouzaud, J.N., Clinard, C., Robert, F., 2005. Size discontinuity

569 between interstellar and chondritic aromatic structures: A high-resolution 570 transmission electron microscopy study. Geochimica et Cosmochimica Acta 69, $5713911-3918$.

572 Francis, J.T., Hitchcock, A.P., 1992. Inner-shell spectroscopy of a para573 benzoquinone, hydroquinone, and phenol - distinguishing quinoid and 574 benzenoid structures. Journal of Physical Chemistry 96, 6598-6610. 
575 Franklin, R.E., 1951. Crystallite growth in graphitizing and non-graphitizing

576 carbons. Proceedings of the Royal Society, Mathematical, Physical and

577 Engineering Sciences 209, 196-218.

578 Gabriel, K.R., 1971. The biplot graphic display of matrices with application to 579 principal component analysis. Biometrika 58, 453-467.

580 Glaser, B., Birk, J.J., 2012. State of the scientific knowledge on properties and 581 genesis of Anthropogenic Dark Earths in Central Amazonia (terra preta de 582 Índio). Geochimica et Cosmochimica Acta 82, 39-51.

583 Gocke, M., Kuzyakov, Y., Wiesenberg, G.L.B., 2013. Differentiation of plant 584 derived organic matter in soil, loess and rhizoliths based on n-alkane molecular 585 proxies. Biogeochemistry 112, 23-40.

586 Guo, Y., Bustin, R.M., 1998. FTIR spectroscopy and reflectance of modern 587 charcoals and fungal decayed woods: implications for studies of inertinite in 588 coals. International Journal of Coal Geology 37, 29-53.

589 Hammes, K., Smernik, R., Skjemstad, J., Herzog, A., Vogt, U., 2006. Synthesis 590 and characterisation of laboratory-charred grass straw (Oryza saliva) and 591 chestnut wood (Castanea sativa) as reference materials for black carbon 592 quantification. Organic Geochemistry 37, 1629-1633.

593 Harvey, O.R., Herbert, B.E., Kuo, L.-J., Louchouarn, P., 2012a. Generalized 594 two-dimensional perturbation correlation infrared spectroscopy reveals 595 mechanisms for the development of surface charge and recalcitrance in plant596 derived biochars. Environmental Science \& Technology 46, 10641-10650.

597 Harvey, O., Kuo, L.-J., Zimmerman, A., Louchouarn, P., Amonette, J., Herbert, 598 B., 2012b. An index-based approach to assessing recalcitrance and soil carbon 
599 sequestration potential of engineered black carbons (biochars). Environmental 600 Science \& Technology 46, 1415-1421.

601 Keiluweit, M., Kleber, M., Sparrow, M.A., Simoneit, B.R.T., Prahl, F.G., 2012.

602 Solvent-extractable polycyclic aromatic hydrocarbons in biochar: influence of 603 pyrolysis temperature and feedstock. Environmental Science \& Technology 46, 604 9333-9341.

605 Keiluweit, M., Nico, P.S., Johnson, M.G., Kleber, M., 2010. Dynamic molecular 606 structure of plant biomass-derived black carbon (biochar). Environmental 607 Science \& Technology 44, 1247-1253.

608 Knicker, H., 2011. Pyrogenic organic matter in soil: Its origin and occurrence, 609 its chemistry and survival in soil environments. Quaternary International 243, $610 \quad 251-263$.

611 Kuznetsova, A., Popova, I., Yates, J.T., Bronikowski, M.J., Huffman, C.B., Liu, 612 J., Smalley, R.E., Hwu, H.H., Chen, J.G.G., 2001. Oxygen-containing functional 613 groups on single-wall carbon nanotubes: NEXAFS and vibrational 614 spectroscopic studies. Journal of the American Chemical Society 123, 1069961510704.

616 Lehmann, J., Czimczik, C., Laird, D., Sohi, S., 2009. Stability of biochar in soil, 617 in: Lehmann, J., Joseph, S. (Eds.), Biochar for environmental management: 618 science and technology. Earthscan: London, UK, pp. 183-206.

619 Lehmann, J., Joseph, S., 2009. Biochar for environmental management - an 620 introduction. In: Lehmann, J., Joseph, S. (Eds.), Biochar for Environemental 621 Management: Science and Technology. Earthscan, London, UK, pp. 1-12. 
622 Lua, A.C., Yang, T., Guo, J., 2004. Effects of pyrolysis conditions on the

623 properties of activated carbons prepared from pistachio-nut shells. Journal of

624 Analytical and Applied Pyrolysis 72, 279-287.

625 Manyà , J., 2012. Pyrolysis for biochar purposes: a review to establish current

626 knowledge gaps and research needs. Environmental Science \& Technology 46, $627 \quad 7939-7954$.

628 Mardia, K.V., Kent, J.T., Bibby, J.M., 1979. Multivariate analysis. Academic 629 Press.

630 McBeath, A., Smernik, R., Plant, E., 2011. Determination of the aromaticity 631 and the degree of aromatic condensation of a thermosequence of wood charcoal 632 using NMR. Organic Geochemistry 42, 1194-1202.

633 McBeath, A.V., Smernik, R.J., 2009. Variation in the degree of aromatic 634 condensation of chars. Organic Geochemistry 40, 1161-1168.

635 McNaught, A.D., Wilkinson, A., 1997. IUPAC. Compendium of Chemical

636 Terminology., 2nd Edition ed. Blackwell Scientific Publications, Oxford.

637 Meyer, S., Glaser, B., Quicker, P., 2011. Technical, economical, and climate-

638 related aspects of biochar production technologies: a literature review.

639 Environmental Science \& Technology 45, 9473-9483.

640 Moore, A., Owen, N., 2001. Infrared spectroscopic studies of solid wood. Applied 641 Spectroscopy Reviews 36, 65-86.

642 Mukome, F.N.D., Zhang, X., Six, J., Parikh, S., Parikh, S.J., 2013. Use of

643 chemical and physical characteristics to investigate trends in biochar

644 feedstocks. Journal of Agricultural and Food Chemistry 61, 2196-2204. 
645 Nguyen, B., Lehmann, J., Hockaday, W., Joseph, S., Masiello, C., 2010.

646 Temperature sensitivity of black carbon decomposition and oxidation.

647 Environmental Science \& Technology 44, 3324-3331.

648 Preston, C.M., Schmidt, M.W.I., 2006. Black (pyrogenic) carbon: a synthesis of 649 current knowledge and uncertainties with special consideration of boreal 650 regions. Biogeosciences 3, 397-420.

651 R, 2011. R: A Language and Environment for Statistical Computing. R 652 Foundation for Statistical Computing.

653 Rutherford, D.W., Wershaw, R.L., Rostad, C.E., Kelly, C.N., 2012. Effect of 654 formation conditions on biochars: Compositional and structural properties of 655 cellulose, lignin, and pine biochars. Biomass and Bioenergy 46, 693-701.

656 Schmidt, M.W.I., Noack, A.G., 2000. Black carbon in soils and sediments: 657 Analysis, distribution, implications, and current challenges. Global 658 Biogeochemical Cycles 14, 777-793.

659 Schneider, M.P.W., Hilf, M., Vogt, U.F., Schmidt, M.W.I., 2010. The benzene 660 polycarboxylic acid (BPCA) pattern of wood pyrolyzed between $200{ }^{\circ} \mathrm{C}$ and $6611000{ }^{\circ} \mathrm{C}$. Organic Geochemistry 41, 1082-1088.

662 Schneider, M.P.W., Smittenberg, R., Dittmar, T., Schmidt, M.W.I., 2011.

663 Comparison of gas with liquid chromatography for the determination of 664 benzenepolycarboxylic acids as molecular tracers of black carbon. Organic 665 Geochemistry 42, 275-282.

666 Setton, R., Bernier, P., Lefrant, S., 2002. Carbon molecules and materials. CRC 667 Press. 
668 Shafizadeh, F., 1982. Introduction to pyrolysis of biomass. Journal of Analytical 669 and Applied Pyrolysis 3, 283-305.

670 Simoneit, B.R.T., 2002. Biomass burning - A review of organic tracers for

671 smoke from incomplete combustion. Applied Geochemistry 17, 129-162.

672 Simoneit, B.R.T., Elias, V.O., 2000. Organic tracers from biomass burning in

673 atmospheric particulate matter over the ocean. Marine Chemistry 69, 301-312.

674 Singh, B.P., Cowie, A.L., Smernik, R.J., 2012. Biochar carbon stability in a 675 clayey soil as a function of feedstock and pyrolysis temperature. Environmental 676 Science \& Technology 46, 11770-11778.

677 Stekhoven, D., Buehlmann, P., 2012. MissForest--non-parametric missing

678 value imputation for mixed-type data. Bioinformatics 28, 112-118.

679 Wang, T., Camps-Arbestain, M., Hedley, M., 2013. Predicting C aromaticity of

680 biochars based on their elemental composition. Organic Geochemistry 62, 1-6.

681 Wiedemeier, D.B., Brodowski, S., Wiesenberg, G.L.B., 2014. Pyrogenic

682 molecular markers: Linking PAH with BPCA analysis. Chemosphere 119, 432683437.

684 Wiedemeier, D.B., Hilf, M.D., Smittenberg, R.H., Haberle, S.G., Schmidt, 685 M.W.I., 2013. Improved assessment of pyrogenic carbon quantity and quality in 686 environmental samples by high-performance liquid chromatography. Journal of 687 Chromatography A 1304, 246-250.

688 Wiesenberg, G.L.B., Gocke, M., Kuzyakov, Y., 2010. Fast incorporation of root689 derived lipids and fatty acids into soil - evidence from a short term multiple 690 pulse labelling experiment. Organic Geochemistry 41, 1049-1055. 
691 Wiesenberg, G.L.B., Lehndorff, E., Schwark, L., 2009. Thermal degradation of 692 rye and maize straw: lipid pattern changes as a function of temperature.

693 Organic Geochemistry 40, 167-174.

694 Wolf, M., Lehndorff, E., Wiesenberg, G.L.B., Stockhausen, M., Schwark, L., 695 Amelung, W., 2013. Towards reconstruction of past fire regimes from

696 geochemical analysis of charcoal. Organic Geochemistry 55, 11-21.

697 Wood, D.J., 1988. Characterization of charcoals by drift. Mikrochimica Acta 2, $698 \quad 167-169$.

699 Yunker, M.B., Macdonald, R.W., Vingarzan, R., Mitchell, R.H., Goyette, D., 700 Sylvestre, S., 2002. PAHs in the Fraser River basin: a critical appraisal of PAH 701 ratios as indicators of PAH source and composition. Organic Geochemistry 33, $702 \quad 489-515$.

703

704

705 